\title{
Canal Transportation, Centering Ability and Maintain Canal Curvature of Sendoline Versus Protaper Universal Rotary Nickel Titanium Files in Preparing Curved Root Canals: An In Vitro Study
}

\author{
Ahmed Mohamed Ahmed Ali Salama ${ }^{1 *}$, Shrief Adel El-Khodary ${ }^{2}$ and Wafaa Ahmed Omar Segari ${ }^{3}$ \\ ${ }^{1}$ MSD Endodontic, Faculty of Dentistry, Cairo University, Egypt \\ ${ }^{2}$ Lecturer of Endodontics, Department of Endodontics, Faculty of Dentistry, Cairo University, Egypt \\ ${ }^{3}$ Associate Professor of Endodontics, Department of Endodontics, Faculty of Dentistry, Cairo University, Egypt \\ *Corresponding Author: Ahmed Mohamed Ahmed Ali Salama, MSD Endodontic, Faculty of Dentistry, Cairo University, Egypt.
}

Received: October 15, 2019; Published: November 11, 2019

DOI: $10.31080 /$ ASDS.2019.03.0697

\begin{abstract}
Objective: The purpose of this study was to evaluate the shaping ability of S5 rotary system in relation to Pro Taper Universal system in preparation moderately curved root canal their effect on the canal transportation, centering ability and canal curvature change. Materials and Methods: Collected thirty mesiobuccally root canals of extracted human mandibular first molar were divided into two equal groups; Pro Taper and S5. The samples were mounted in two moulds of acrylic resin for pre-instrumentation imaging using cone beam computed tomography (CBCT). After root canal instrumentation, post-instrumentation imaging using CBCT was done with the exacted parameters of the pre-instrumentation imaging. The pre and post-instrumentation CBCT images were superimposed to measure the dentin thickness at three root canal levels; Canal transportation and centering ability were recorded according to formula introduced by Gambill., et al. (1996), while the change in the angle of canal curvature was recorded following Estrela., et al. (2008).

Statistical Analysis: Data was tabulated and statistically analyzed; Independent samples t-test was used for comparing the variables between the two groups at each root canal level and also was used for comparing the percentage of change in the canal curvature angle between the two groups. The significance level is considered at $\mathrm{P} \leq 0.05$.

Results: There was no statistically significant difference between the two rotary systems in canal transportation except at the coronal level; S5 recorded statistically lower mean value of root canal transportation than Pro Taper system. The centering ratios and the changes in the angles of canal curvature after the use of both systems were not statistically significant. None of the used systems showed perfect centering ability.

Conclusion: Under limitations of this in vitro study, it can be concluded that; preparation of moderately curved mesio-buccal root canals with S5 was associated with lesser coronal transportation and similar middle and apical transportation, centering ability, and canal curvature change when compared to Pro Taper.
\end{abstract}

Keywords: Canal Transportation; Centering Ability; Canal Curvature Change; Pro Taper Universal; S5; CBCT

\section{Introduction}

Cleaning and shaping is one of the most important steps for the success of root canal treatment. The criteria of canal shaping include developing a continuously tapered funnel shape from the canal orifice to the apex while maintaining the original shape of the canal without altering the canal curvature [1]. However, complex anatomy specifically root canal curvatures present a challenge to enlarging instruments and might accompany by a number of 
endodontic complications such as ledge, perforation, and canal transportation [2].

Nickel-titanium ( $\mathrm{Ni} \mathrm{Ti}$ ) rotary systems have revolutionized root canal instrumentation by shaping the root canal with less complications due to its high flexibility, resiliency and shape memory [3]. Nevertheless, manufacturers keep introducing $\mathrm{Ni} \mathrm{Ti}$ systems with new designs, manufacturing processes, materials and different kinematics [4]. It is important for clinicians to have an information about the clinical performance of these newly introduced systems during root canal instrumentation. So, continuous research is required to evaluate the shaping performance of these newly introduced systems and make a decision regarding which instrument is an appropriate for root canal preparation.

S5 (Sendoline, Täby, Sweden) is a new Ni Ti rotary system made of heat-treated nickel titanium alloy and has a unique S-shape profile and long progressive flutes $[5,6]$. According to the manufacturer, this design ensures enhanced debris removal and reduces the risk of instrument fractures. The series of S5 instruments comprises five instruments: S1 $(0.08 / 30)$, S2 $(0.06 / 30)$, S3 $(0.04 / 30)$, S4 $(0.04 / 25)$, and S5 $(0.04 / 20)[5,6]$.

Literature research results reported that the shaping ability of S5 was examined in few studies [6-8]. In one study, S5 recorded similar transportation with Reciprocal and twisted file (TF) at the apical part, and greater transportation than TF at the middle part [6]. In the other study, S5 recorded less transportation than Pro Taper Universal and wave one and similar transportation with GT series X [7]. The last study was examined canal transportation only in extracted teeth. In this study S5 caused the highest amount of transportation in the coronal third compared with Pro Taper and Race [8].

To our knowledge, there is a lack of data regarding centering ability and change in the canal curvature angle of S5 rotary system in shaping natural extracted teeth especially with canal curvature. Considering the impact of the natural conditions of human teeth such as dentin hardness and root canal cross sections and curvatures on the shaping performance results, it is important to assess the shaping ability of S5 in human extracted curved root canals and in relation to widely assessed $\mathrm{Ni}$ Ti system.
The Pro Taper Universal (Dentsply, Maillefer, Ballaigues, Switzerland) is a conventional NiTi rotary system. The shaping ability of Pro Taper system is assessed widely in comparison to other NiTi systems. Studied recorded it's efficiently in preparing root canals, even those with severe curvature and with no definitive procedural errors [9-11].

The aim of this study was to evaluate the shaping ability of S5 rotary system in comparison to Pro Taper Universal system in preparation moderately curved mesiobuccally root canal of extracted mandibular molars using CBCT based on the following criteria; canal transportation, centering ability and change in the canal curvature angle.

\section{Materials and Methods}

This study was carried out on thirty mesiobuccally root canals of extracted human mandibular molars. The teeth were selected from a collection of extracted human teeth with the following inclusion criteria; mature mesial root apices, average mesial root length from 20 to $22 \mathrm{~mm}$, separated mesiobuccally canal with the angle of curvature ranging $20-40^{\circ}$ (according to Schneider) [12] and with apical width nearly equal to size 15 - $20 \mathrm{~K}$ file (Mani Inc., Tochigikan, Japan). The teeth that exhibited root caries, crack, fracture or external root resorption were excluded.

Preoperative radiographic examinations (Soredex Min Ray, Helsinki, Fenland) have been done for the teeth to exclude the root canals with calcification and internal resorption and include only teeth with separate mesiobuccally root canals. The collected teeth were cleaned from any soft tissue and hard deposits by using an ultrasonic scaler and immersed for ten minutes in 5.25\% sodium hypochlorite (NaOCl) (Clorox, Tenth of Ramadan City, Egypt). Subsequently, the teeth were stored in saline solution until used.

After access cavity preparation, A 10-15 K-file (Mani Inc., Tochigi-kan, Japan) was inserted in the mesiobuccally canal to check the patency, apical width and to measure the root canal curvature angle according to Schneider [12]. The root canals with a range of curvature $20^{\circ}-40^{\circ}$ were only included in the study.

The distal roots with the respective part of the crowns of all samples were sectioned at the furcation level using stainless steel disc (Isomet R 4000 Unear Precision Saw, Buehler, England) under 
coolant and discarded. The root canal length was adjusted to the length of $18-19 \mathrm{~mm}$ by flattening the occlusal surface using a diamond stone. Subsequently, the working length was adjusted to be $1 \mathrm{~mm}$ shorter, i.e. $17-18 \mathrm{~mm}$.

The thirty samples collected for this study were divided into two equal groups; 1 and 2, according to the NiTi system used for instrumentation. Samples concealment was done by one clinician as follows; each sample was inserted in a separate envelope, the envelopes were shuffled, then a number from 1 to 30 was written on each envelope. Another clinician placed fifteen envelopes in group 1 (Pro Taper group) and fifteen envelopes in group 2 (S5 group) according to the table of the random sequence. The random sequence was generated using the random sequence generator website (http://www.random.org/sequences/).

The envelopes were reopened and the samples were vertically arranged in two arch shaped moulds of acrylic resin (Orthoplast; Vertex-dental by J.V, Rotterdam, Netherlands) with the buccal surfaces of all teeth facing in the same direction.

All samples were subjected for pre-instrumentation imaging using CBCT. Images were acquired using iCAT Next Generation scanner (ISI, USA). The following operating protocol for the preinstrumentation as well as post-instrumentation CBCT scans was used: $120 \mathrm{kVp}, 37.07 \mathrm{mAs}$, voxel size $0.125 \mathrm{~mm}$, scanning time 26.9 sec, and field of view $16 \times 4 \mathrm{~cm}$.

The samples were prepared by the investigator according to manufacturers' instructions $[13,14]$ for each group. In both groups, irrigation was done between each two successive files with $2 \mathrm{ml}$ of $5.25 \% \mathrm{NaOCl}$ solution and plastic syringe with $30-\mathrm{G}$ needle. Root canal patency was maintained using a $10 \mathrm{~K}$-file between each file.

OnDemand 3D App software (Cybermed, South Korea) was used for the linear and angular measurements. The fusion module of OnDemand 3D App software was employed to automatically superimpose pre-instrumentation and post-instrumentation images, hence guaranteeing measuring dentin thickness at the exact root canal level.

Pre and post-instrumentation CBCT axial images were superimposed and dentin thickness of each sample was evaluated at three root canal levels for each sample; $3 \mathrm{~mm}, 5 \mathrm{~mm}$, and $12 \mathrm{~mm}$ from the tooth apex representing the apical, middle, and coronal third at both scans simultaneously. At each root canal level, dentin thickness was measured at the buccal, lingual, mesial and distal aspects of the canal lumen. Axial levels assigned for recording dentin thickness were decided by the end of each of these four lines.

Canal transportation, centering ability and change in the angle of canal curvature after using both file systems were evaluated as follows:

\section{Canal transportation}

Canal transportation was evaluated using method developed by Gambill., et al. (1996) [15] by measuring the shortest distance from the edge of the canal to the periphery of the root (mesial, distal, buccal and lingual) on pre- and post-instrumentation images (Figure1). The following formula was utilized for calculation the transportation in both mesio-distal and buco-lingual directions at each root canal level as follows:

Mesiodistally: (M1-M2)-(D1-D2) Buccolingually: (B1-B2)(L1-L2) The absolute results of the formula were used to calculate the transportation value while the original results were used to measure the direction of the transportation. The Result Zero of the equation means no transportation, while the positive results indicate (mesial/buccal) transportation, and the negative results indicate (distal/lingual) transportation.

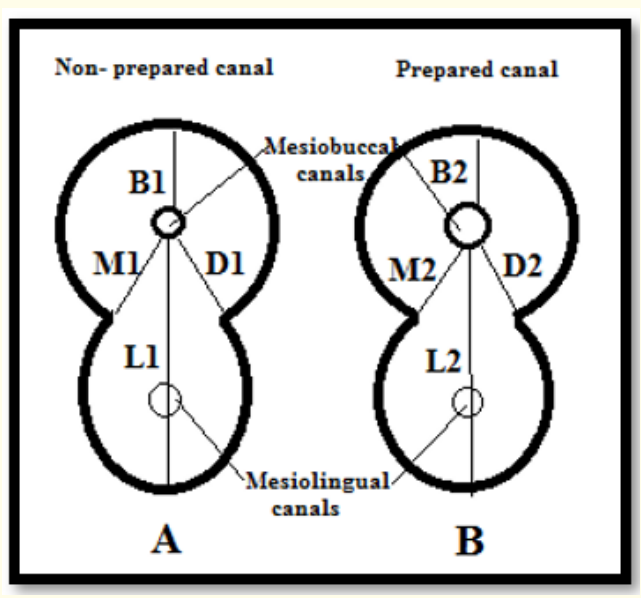

Figure 1: Diagram showing canal transportation and centering ability evaluation based on Gambill's formula; the cross-section of non-prepared canal (A) and prepared canal (B). M1, B1, L1 and D1 are dentin thickness before instrumentation, while M2, B2, L2 and D2 are dentin thickness after instrumentation. 
Canal Transportation, Centering Ability and Maintain Canal Curvature of Sendoline Versus Protaper Universal Rotary Nickel Titanium Files in Preparing Curved Root Canals: An In Vitro Study

\section{Canal centering ratio}

The centering ratio indicates the ability of the instrument to keep centered inside the root canal during instrumentation. The centering ratio at mesiodistally and buccolingually directions at each root canal level have been measured by formula introduced by Gambill., et al. (1996) [15] as follows;

Mesiodistally: (M1-M2)/(D1-D2) or (D1-D2)/(M1-M2)

Buccolingually: (B1-B2)/(L1-L2) or (L1-L2)/(B1-B2)

The results of the equations with the lowest numerator were used. If the result was equal one, it indicated perfect centering ability, while if the result was less than one, this indicated less centering ability (i.e. the less ability of the instrument to keep centralized inside the canal).

Post-instrumentation canal curvature change

The change in the root canal curvature after using each file system was calculated based on the change in the angle of canal curvature. The CBCT sagittal cut was utilized to measure the preand post-instrumentation angle of curvature according to the Schneider's method as mentioned before (Figure 2). The percentage of the change in canal curvature angle after instrumentation was calculated using the following formula according to Estrela., et al. (2008); [16],

Angle canal curvature post preparation - Angle canal curvature before preparation Angle canal curvature before preparation

\section{Statistical Analysis}

Shapiro-Wilk test of normality was used to test the normality hypothesis of all quantitative variables for further choice of appropriate parametric and non-parametric tests. Mostly the variables were found normally distributed, allowing the use of parametric tests. The means of canal transportation, centering ratio and change in canal curvature angle, including Standard Deviation (SD), the range (Minimum - Maximum), and Standard Error (SE) were calculated. The 95\% confidence interval of the previous values was reported.

Independent samples t-test was used for comparing the variables between the two groups at each root canal levels and also was used for comparing the percentage of change in the canal curvature angle between the two groups. Chi-square test and Fisher exact test are applied to compare the direction of transportation between the two groups. The significance level is considered at $\mathrm{P}$ $\leq 0.05$
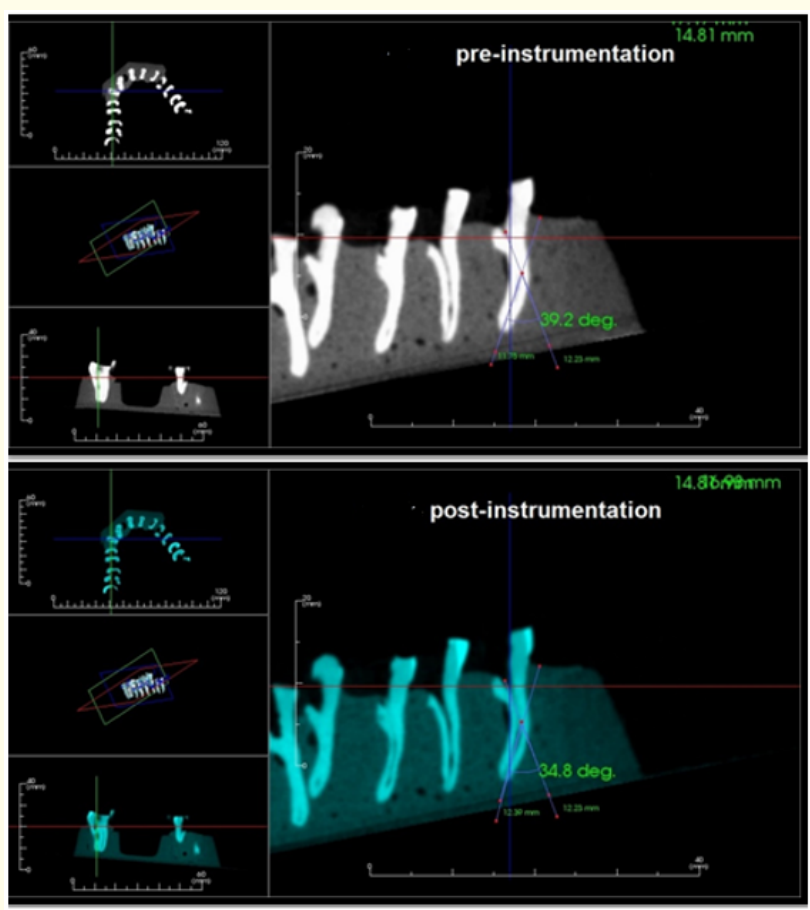

Figure 2: Representative CBCT sagittal slices showing measurement of pre and post instrumentation' angles of root canal curvature.

\section{Results}

Canal transportation

At mesio-distal direction, at the coronal level, Pro Taper demonstrated higher significant mean value of transportation than S5 group ( $p$-value $=0.013$ ). On the other hand, there were no statistically significant differences between the two groups at the middle $(p$-value $=0.407)$ and apical levels ( $p$-value $=0.500)$.

At bucco-lingual direction, S5 recorded higher transportation value at the apical level while Pro Taper recorded higher values at the middle and apical levels. Comparisons of canal transportation between the two groups at each root canal level are not significantly different (Table 1).

\section{Centering ratio}

No statistically significant differences were recorded in the centering ratio values between the two groups at mesiodistally and buccolingually directions at the three root canal levels (Table 2). 
Canal Transportation, Centering Ability and Maintain Canal Curvature of Sendoline Versus Protaper Universal Rotary Nickel Titanium Files in Preparing Curved Root Canals: An In Vitro Study

\begin{tabular}{|c|c|c|c|c|c|c|c|c|}
\hline Directions & Levels & Group & Mean & SD & $\begin{array}{c}\text { Mean } \\
\text { Diffrence }\end{array}$ & \multicolumn{2}{|c|}{$95 \%$ CI } & P-Value \\
\hline \multirow{6}{*}{ Mesiodistally } & \multirow[t]{2}{*}{ Apical } & ProTaper & -0.05 & 0.15 & \multirow[t]{2}{*}{0.04} & \multirow[t]{2}{*}{-0.08} & \multirow[t]{2}{*}{0.15} & \multirow[t]{2}{*}{0.500} \\
\hline & & S5 & -0.09 & 0.16 & & & & \\
\hline & \multirow[t]{2}{*}{ Middle } & ProTaper & -0.08 & 0.19 & \multirow[t]{2}{*}{-0.05} & \multirow[t]{2}{*}{-0.18} & \multirow[t]{2}{*}{0.08} & \multirow[t]{2}{*}{0.407} \\
\hline & & S5 & -0.03 & 0.16 & & & & \\
\hline & \multirow[t]{2}{*}{ Coronal } & ProTaper & -0.07 & 0.11 & \multirow[t]{2}{*}{-0.11} & \multirow[t]{2}{*}{-0.20} & \multirow[t]{2}{*}{-0.02} & \multirow[t]{2}{*}{$0.013^{*}$} \\
\hline & & S5 & -0.04 & 0.12 & & & & \\
\hline \multirow{6}{*}{ Buccolingually } & \multirow[t]{2}{*}{ Apical } & ProTaper & -0.06 & 0.11 & \multirow[t]{2}{*}{0.06} & \multirow[t]{2}{*}{-0.03} & \multirow[t]{2}{*}{0.15} & \multirow[t]{2}{*}{0.182} \\
\hline & & S5 & -0.12 & 0.14 & & & & \\
\hline & \multirow[t]{2}{*}{ Middle } & ProTaper & -0.07 & 0.13 & \multirow[t]{2}{*}{-0.03} & \multirow[t]{2}{*}{-0.13} & \multirow[t]{2}{*}{-0.07} & \multirow[t]{2}{*}{0.538} \\
\hline & & S5 & -0.04 & 0.13 & & & & \\
\hline & \multirow[t]{2}{*}{ Coronal } & ProTaper & -0.10 & 0.14 & \multirow[t]{2}{*}{-0.03} & \multirow[t]{2}{*}{-0.13} & \multirow[t]{2}{*}{0.06} & \multirow[t]{2}{*}{0.480} \\
\hline & & S5 & -0.07 & 0.12 & & & & \\
\hline
\end{tabular}

Table 1: The results of independent t-test for canal transportation between the two groups at the mesio-distal and bucco-lingual directions.

*Significant at $\mathrm{P} \leq 0.05$

\begin{tabular}{|c|c|c|c|c|c|c|c|c|}
\hline Directions & Levels & Group & Mean & SD & Mean Difference & $\begin{array}{r}95 \\
95 \%\end{array}$ & pper & P-Value \\
\hline \multirow{4}{*}{ Mesiodistally } & \multirow[t]{2}{*}{ Apical } & ProTaper & 0.49 & 0.39 & \multirow[t]{2}{*}{0.14} & \multirow[t]{2}{*}{-0.15} & \multirow[t]{2}{*}{0.44} & \multirow[t]{2}{*}{0.333} \\
\hline & & S5 & 0.35 & 0.35 & & & & \\
\hline & \multirow[t]{2}{*}{ Middle } & ProTaper & 0.33 & 0.38 & \multirow[t]{2}{*}{0.02} & \multirow[t]{2}{*}{-0.24} & \multirow[t]{2}{*}{0.28} & \multirow[t]{2}{*}{0.890} \\
\hline & & S5 & 0.31 & 0.30 & & & & \\
\hline \multirow{8}{*}{ Buccolingually } & \multirow[t]{2}{*}{ Coronal } & ProTaper & 0.44 & 0.29 & \multirow[t]{2}{*}{-0.10} & \multirow[t]{2}{*}{-0.35} & \multirow[t]{2}{*}{0.15} & \multirow[t]{2}{*}{0.435} \\
\hline & & S5 & 0.54 & 0.38 & & & & \\
\hline & \multirow[t]{2}{*}{ Apical } & ProTaper & 0.42 & 0.29 & \multirow[t]{2}{*}{-0.02} & \multirow[t]{2}{*}{-0.25} & \multirow[t]{2}{*}{0.22} & \multirow[t]{2}{*}{0.898} \\
\hline & & S5 & 0.44 & 0.33 & & & & \\
\hline & \multirow[t]{2}{*}{ Middle } & ProTaper & 0.38 & 0.27 & \multirow[t]{2}{*}{0.06} & \multirow[t]{2}{*}{-0.15} & \multirow[t]{2}{*}{0.27} & \multirow[t]{2}{*}{0.564} \\
\hline & & S5 & 0.32 & 0.28 & & & & \\
\hline & \multirow[t]{2}{*}{ Coronal } & ProTaper & 0.45 & 0.25 & \multirow[t]{2}{*}{0.05} & \multirow[t]{2}{*}{-0.16} & \multirow[t]{2}{*}{0.26} & \multirow[t]{2}{*}{0.630} \\
\hline & & S5 & 0.40 & 0.26 & & & & \\
\hline
\end{tabular}

Table 2: The results of independent t-test for centering ability values of the two groups.

*Significant at $\mathrm{P} \leq 0.05$ 
Canal Transportation, Centering Ability and Maintain Canal Curvature of Sendoline Versus Protaper Universal Rotary Nickel Titanium Files in Preparing Curved Root Canals: An In Vitro Study

\section{Post instrumentation canal curvature change}

The mean of change in canal curvature angle is slightly higher in S5 (9.06) than Pro Taper group (8.02) and without significant difference $(p$-value $=0.644)$ (Table 3$)$.

\begin{tabular}{|l|c|c|c|c|c|c|}
\hline Group & Mean & SD & $\begin{array}{c}\text { Mean } \\
\text { Difference }\end{array}$ & \multicolumn{2}{|c|}{$95 \%$ CI } & $\begin{array}{c}\text { P- } \\
\text { Value }\end{array}$ \\
\hline ProTaper & -8.02 & 5.83 & \multirow{2}{*}{1.05} & -3.55 & 5.65 & 0.644 \\
\hline S5 & -9.06 & 6.45 & & & & \\
\hline
\end{tabular}

Table 3: The mean and standard deviation (SD) values of the change in canal curvature angles after using ProTaper and S5 and independent t-test result.

*Significant at $\mathrm{P} \leq 0.05$

\section{Discussion}

There is no standardized technique or parameters for studying the shaping performance of enlarging instruments. Different parameters are used in literature such as change in the root canal cross-sectional area, degree of canal transportation, centering ability, minimum remaining dentine thickness in the mesial and furcal directions, volumetric changes, taper and flow of the prepared root, smoothening of the canal walls, change in curvature angulation, canal aberrations, and working length [17]. In the present study and following other studies [18,15], the shaping ability of both instruments was assessed in terms of three parameters; canal transportation, centering ability and ability to maintain canal curvature. These parameters were used because the most important aspects related to the instruments during root canal shaping is to be centered and to be able to maintain the original shape and curvature of the root canal without transportation. Studies recorded that poorly centered instruments can result in unequal removal of dentin around the instrument and increase the risk of canal transportation $[19,20]$. The sequel of canal transportation might be zipping, elbows, apical transportation and strip perforation. These sequel might hamper adequate cleaning and proper sealing with subsequent persistent periapical tissue irritation and decreasing of the treatment outcome [21].

When comparing the shaping ability of different root canal instruments, Bergmans., et al. [22] reported the importance that they have similar apical preparation diameters for fair comparison [22]. In the present study, the size of apical preparation in S5 group $(\mathrm{S} 3 ; 30 / 0.04)$ is larger than Pro Taper group (F2;25/0.08). However, both manufacturers of both files recommended them to prepare root canals with moderate range of curvatures [14]. Additionally, using the F3(30/0.09) with the same apical diameter of S3 might increase the tendency to canal transportation because of the increase in the taper and metal mass in the core that will decrease the flexibility of the instruments. Furthermore, using larger instruments might predictably remove more dentin which might affected the results $[8,23,24]$.

CBCT imaging was used in the current study for evaluation the shaping ability because it enables reproducible three-dimensional assessment of the root canal system without damaging the samples. CBCT imaging is used in conjunction with OnDemand 3D App software that allow automatic dentin measurements at the exact pre-instrumentation and post-instrumentation root canal levels without human errors. Currently, micro CT is highly recommended for evaluation the shaping ability of instruments because of the high resolution and accuracy, but it is not available in Egypt at this time.

Dentin removal during root canal instrumentation is important because it will lead to removal of infected dentin and produce taper preparation for effective irrigation and obturation [1]. At this time, the optimum amount of dentin thickness to be removed to achieve these objectives without affecting the endodontic outcome and tooth strength was not decided by the studies. Accordingly, the critical value of the change in dentin thickness and canal transportation were not reported yet. It was previously reported by Wu., et al. [25] that the apical transportation more than $0.3 \mathrm{~mm}$ can compromise the apical seal of root canal filling. In the present study, all transportation values after using both instruments are less than $0.3 \mathrm{~mm}$; in apical $(0.05-0.12 \mathrm{~mm})$, middle $(0.03-0.08 \mathrm{~mm})$, and coronal $(0.04-0.10 \mathrm{~mm})$. It might be fair to suppose that these values of canal transportation would not compromise the endodontic outcomes. This indicates the ability of S5 as well as Pro Taper to prepare the root canal, with acceptable amount of transportation that doesn't compromise the apical seal of obturation.

The transportation values recorded by S5 are comparable to Pro Taper system except at the coronal level at mesio-distal direction, where Pro Taper induced significantly higher values of 
transportation than S5. The greater coronal transportation induced by Pro Taper is resulted from its greater taper in relation to S5 at $12 \mathrm{~mm}$ while the shaft diameter of Pro Taper is $1.13 \mathrm{~mm}$ but the shaft diameter of S5 is $0.74 \mathrm{~mm}$. Increase the taper of instrument is directly accompanied by the increase of cross sectional area and hence decrease of the instrument flexibility. This finding is in agreement with of Paque., et al. [26], Bergmans., et al. [22], Wu H., et al. [27], Özer., et al. [28], Navós., et al. [29], and Bonaccorso A., et al [30].They recorded higher coronal transportation values after using Pro Taper.

The similar transportation values induced by S5 and Pro Taper at the middle and apical levels could be explained by the similar shaft cross section diameter and similar alloy type of the two instruments. At apical level ( $3 \mathrm{~mm}$ from the apex), the shaft diameter of F2 (25/0.08) and S3 (30/0.04) are $0.41 \mathrm{~mm}$ and 0.38 $\mathrm{mm}$ respectively. Once again, this finding was in disagreement with Saberi and Aremesh [8], who recorded higher apical transportation values after using Pro Taper compared to S5. The reason for this disagreement is probably again due to the use of the F3 file (30/0.09) and S2(30/0.06) for apical preparation, where they have progressive taper of the instruments, reduced flexibility and increased tip stiffness.

Concerning the centering ability, neither S5 nor Pro Taper remained perfectly centralized within the root canal in any prepared sample. Both system recorded similar centering ratios, in both mesiodistally and buccolingually directions at the three root canal levels. The similar centering ability of the two instruments might be attributed to the similar type of alloy, tip design and movement kinematics. Both systems are made of convential Ni Ti alloy with non-cutting tip and prepared the canal using rotation motion [3133]. To date, there is no study investigated the centering ability of S5. Lack of perfect centering values of S5 as well as Pro Taper might be attributed to the range of root canal curvature used in the present study that presented a challenge for both instruments because of their limited flexibility as both systems are made of conventional Ni Ti alloy. For S5, the type of heate treatment ....is not known.

Maintaining the original canal shape during preparation including canal curvature is a pre request to avoid or reduce the complications. The agreed extent of canal curvature change that doesn't affect the outcome of endodontic treatment has not been reported yet. Hulsmann (2000) [34] reported that straightening of the canal should not be tolerable, if values of canal angle change are between $5^{\circ}$ and $7.7^{\circ}$.

The changes in the canal curvature angles after using Pro Taper and S5 rotary systems are comparable. The means of the change in the canal curvature angle after using Pro Taper and S5 were $8.02 \pm 5.83$ and $9.06 \pm 6.45$ respectively. These values are nearly similar with Pro Taper values of canal curvature changes reported in previous studies $[34,35]$. To date there is no study investigated the canal curvature changes after using S5. Once again, this finding can be explained by similarity of both instruments in the following; the type of alloy, noncutting tip design and movement kinematics $[34,36]$.

In the present study, effort has been done to decrease the variability between the samples including; length, apical diameter and the angle of root canal curvature. However, more standardization of the samples is required to take into consideration the range of root canal curvature, the radius and position of the curve.

\section{Conclusion}

Under limitations of this in vitro study and on the basis of the results, it can be concluded that; preparation of moderately curved mesio-buccal root canals with S5 was associated with lesser coronal transportation and similar middle and apical transportation, centering ability, and canal curvature change when compared to Pro Taper. The values of canal transportation in the present study of S5 and Pro Taper systems are considered acceptable. Both S5 and Pro Taper were not able to achieve perfect centering ability during root canal preparation.

\section{Conflict of Interest}

The authors deny any conflicts of interest in this study.

\section{Bibliography}

1. Schafer E and Florek H. "Efficiency of rotary nickel-titanium K3 instruments compared with stainless steel hand K-Flexofile. Part 1. Shaping ability in simulated curved canals". International Endodontic Journal 36.3 (2003): 199-207.

2. Weine F, et al. "The effect of preparation procedures on original canal shape and on apical foramen shape". Journal of Endodontics 1.8 (1975): 255-262. 
3. Pentelescu C., et al. "In vitro evaluation of root canal preparation with two rotary instrument systems Pro Taper and Hero Shaper". Clujul Medical 88 (2015): 395-402.

4. Hiran-us S., et al. "Shaping ability of ProTaper NEXT, ProTaper Universal and iRace files in simulated S-shaped canals". Australian Endodontic Journal 42 (2016): 32-36.

5. S5 rotary files (2015).

6. Altunbas D., et al. "Shaping ability of reciprocating single-file and full-sequence rotary instrumentation systems in simulated curved canals". European Journal of Dentistry 9 (2015): 346-351.

7. Ceyhanli K., et al. "Shaping ability of two M-wire and two traditional nickel-titanium instrumentation systems in S-shaped resin canals". Nigerian Journal of Clinical Practice 18 (2015): 713.

8. Saberi E and Aramesh B. "Computed tomography evaluation of root canal transportation using ProTaper, Race and Sendoline rotary systems: an ex vivo study". Clinical, Cosmetic and Investigational Dentistry 10 (2018): 93-98.

9. Park H., et al. "Root canal volume change and transportation by Vortex Blue, ProTaper Next, and ProTaper Universal in curved root canals". Restorative Dentistry and Endodontics 43.1 (2017): e3.

10. Raut A., et al. "Comparative analysis of cleaning ability of three nickel-titanium rotary systems: ProTaper universal, K3 and mtwo: An in vitro scanning electron microscopic study". Nigerian Postgraduate Medical Journal 23.4 (2016): 221-226.

11. Moe K., et al. "Root canal shaping effect of instruments with offset mass of rotation in the mandibular first molar: A micro-computed tomographic study". Journal of Endodontics 44 (2018): 822-827.

12. Schilder H. "Cleaning and shaping the root canal". Dental Clinics of North America 18.2 (1974): 269-296.

13. Pro Taper Universal direction for use (2017).

14. S5 Rotary Files (2015).

15. Gambill M., et al. "Comparison of nickel-titanium and stainless steel hand-file instrumentation using computed tomography". Journal of Endodontics 22 (1996): 369-375.
16. Estrela C., et al. "Method for determination of root curvature radius using cone-beam computed tomography images". Brazilian Dental Journal 19 (2008): 114-118.

17. Short J., et al. "A comparison of canal centering ability of four instrumentation techniques". Journal of Endodontics 23 (1997): 503-507.

18. Stern S., et al. "Changes in centring and shaping ability using three nickel-titanium instrumentation techniques analysed by micro-computed tomography ( $\mu \mathrm{CT})$ ". International Endodontic Journal 45 (2012): 514-523.

19. Yamamura B., et al. "Comparing canal transportation and centering ability of EndoSequence and Vortex rotary files by using micro-computed tomography". Journal of Endodontics 38 (2012): 1121-1125.

20. Gergi R., et al. "Comparison of canal transportation and centering ability of Twisted Files, Pathfile-ProTaper System, and stainless steel hand K-files by using computed tomography". Journal of Endodontics 36 (2010): 904-907.

21. García M., et al. "A Comparison of apical transportation between ProFile and RaCe rotary instruments". Journal of Endodontics 38 (2012): 990-992.

22. Bergmans L., et al. "Progressive versus constant tapered shaft design of NiTi rotary instruments". Journal of Dental Research 82 (2003): 478-478.

23. Vaudt J., et al. "Ex vivo study on root canal instrumentation of two rotary nickel-titanium systems in comparison to stainless steel hand instruments". International Endodontic Journal 42 (2009): 22-33.

24. Zhang L., et al. "The shaping effect of the combination of two rotary nickel-titanium instruments in simulated S-shaped canals". Journal of Endodontics 34 (2008): 456-458.

25. Wu M., et al. "Leakage along apical root fillings in curved root canals. Part I: effects of apical transportation on seal of root fillings". Journal of Endodontics 26 (2000): 210-216.

26. Paque F., et al. "Comparison of root canal preparation using RaCe and ProTaper rotary Ni-Ti instruments". International Endodontic Journal 38 (2005): 8-16.

27. Wu H., et al. "Shaping ability of ProTaper Universal, WaveOne and ProTaper Next in simulated L-shaped and S-shaped root canals". BMC Oral Health 15 (2015): 27. 
28. Özer S. "Comparison of root canal transportation induced by three rotary systems with noncutting tips using computed tomography". Oral Surgery, Oral Medicine, Oral Pathology, and Oral Radiology 111 (2011): 244-250.

29. Navós B., et al. "Centering and transportation: in vitro evaluation of continuous and reciprocating systems in curved root canals". Journal of Conservative Dentistry 19 (2016): 478-481.

30. Bonaccorso A., et al. "Shaping ability of four nickel-titanium rotary instruments in simulated S-shaped canals". Journal of Endodontics 35 (2009): 883-886.

31. Elnaghy A and Elsaka S. "Shaping ability of ProTaper Gold and ProTaper Universal files by using cone-beam computed tomography”. Indian Journal of Dental Research 27 (2016): 3741.

32. Yang G., et al. "Shaping ability of progressive versus constant taper instruments in curved root canals of extracted teeth". Australian Endodontic Journal 40 (2007): 707-714.

33. Aguiar C., et al. "Comparison of the centring ability of the ProTaperTM and ProTaper UniversalTM rotary systems for preparing curved root canals". Australian Endodontic Journal 39 (2013): 25-30.

34. Guelzow A., et al. "Comparative study of six rotary nickel-titanium systems and hand instrumentation for root canal preparation". International Endodontic Journal 38 (2005):743-752.

35. Capar I., et al. "Effects of ProTaper Universal, ProTaper Next, and HyFlex instruments on crack formation in dentin". Journal of Endodontics 40 (2014):1482-1484.

36. Kum K., et al. "Shaping ability of three ProFile Rotary instrumentation techniques in simulated resin root canals". Journal of Endodontics 26 (2000): 719-723.

Volume 3 Issue 12 December 2019 (C) All rights are reserved by Ahmed Mohamed Ahmed Ali Salama., et al. 